\title{
Cytogenetic abnormalities predict treatment-free interval and response to therapy in previously untreated chronic lymphocytic leukemia patients
}

\author{
M. GIERTLOVA ${ }^{1}$, M. HAJIKOVA ${ }^{1}$, J. VASKOVA ${ }^{2}$, A. KAFKOVA ${ }^{3}$, N. STECOVA ${ }^{3}$, L. MIROSSAY ${ }^{1}$, A. KARABINOS, E. TOTHOVA ${ }^{3}$, M. SARISSKY $^{*}$
}

${ }^{1}$ Central Laboratory of Clinical Cytometry, Department of Pharmacology, Faculty of Medicine, University of P.J. Safarik, Trieda SNP 1, 04011 Kosice, Slovakia,e-mail: marek.sarissky@upjs.sk; ${ }^{2}$ SEMBID, s.r.o. - Laboratory of Medical Genetics, Presov, Slovakia; ${ }^{3}$ Department of Hematology and Oncohematology, Faculty of Medicine, University of P.J. Safarik \& L. Pasteur University Hospital, Kosice, Slovakia

Received Jun 8, 2010

\begin{abstract}
We evaluated the prognostic impact of chromosomal abnormalities as detected by interphase fluorescence in situ hybridization (iFISH) in 86 chronic lymphocytic leukemia (CLL) patients. Overall, 39 of 86 (45\%) patients displayed one (35\%) or more (10\%) chromosomal abnormalities, del13q (31\%) being more frequently detected than trisomy 12 (19\%) followed by del11q (17\%), del17p (6\%) and del6q (5\%). Significant differences in the treatment free intervals (TFIs) were observed among individual cytogenetic subgroups ( $\mathrm{p}=0.027$ ) with the shortest mean TFIs in subgroups with del17p, del11q and trisomy $12(10$, 12 and 14 months, respectively) as compared to subgroups with normal cytogenetics (38 months) and del13q (68 months). Poor response to therapy was observed in subgroups with del11q $(\mathrm{p}=0.044)$ and trisomy $12(\mathrm{p}=0.047)$ while patients with normal cytogenetics had good response $(\mathrm{p}=0.003)$. Furthermore, del17p and del11q were associated with highest tumor burden and disease activity as reflected by corresponding laboratory data.
\end{abstract}

Key words. chronic lymphocytic leukemia, CLL; chromosomal abnormalities, iFISH; treatment-free interval, response to therapy

Chronic lymphocytic leukemia (CLL) is the most frequent adult leukemia in the Western world accounting for approximately $30 \%$ of all leukemias [1]. It is characterized by a highly variable clinical course. In some patients, almost asymptomatic course without treatment necessity and survival up to two decades is present. In others, rapid progression and resistance to standard treatment with short survival is observed.

For decades, clinical staging systems developed by Rai and Binet $[2,3]$ have remained the keystones for clinical decision-making. However, these clinical staging systems alone are not sufficient to estimate the individual prognosis reliably, particularly in patients with the early-stage disease [4]. Therefore, in efforts to assess the prognosis of patients with CLL more accurately, a number of prognostic factors have been identified. These include clinical characteristics (age, gender, performance status) and laboratory parameters reflecting the tumor burden or disease activity (lymphocyte count, level of lactate dehydrogenase, bone marrow infiltration pattern or lymphocyte doubling time). Recently, more informative biological parameters have been determined, such as soluble CD23, $\beta$-2-microglobulin, thymidine kinase, the mutation status of the variable segments of the immunoglobulin heavy chain genes $(\mathrm{IgVH})$ or surrogate markers for these factors (CD38, ZAP-70) and most importantly, recurrent chromosomal abnormalities [5].

By conventional cytogenetic analysis, clonal chromosomal abnormalities were detected in only 40 to $50 \%$ of cases, the most common being trisomy 12 and abnormalities of chromosome bands 13q14 and 14q32 [6]. When interphase fluorescence in situ hybridization (iFISH) was used, abnormalities were observed in up to $80 \%$ of the patients; the most common gene defects detected by this method were deletions involving chromosome bands 13q14, 11q22.3-q23.1 and 17p13 as well as trisomy 12 [7-10].

Deletion of the TP53 gene which is encoded at $17 \mathrm{p} 13$ has been shown to be associated with resistance to treatment and represents an independent marker for poor survival [7]. Deletion of 11q has been associated with extensive nodal involvement, rapid disease progression, and short survival times $[11,12]$. In contrast, sole abnormalities of chromosome $13 q 14$ have been linked to a more favorable clinical outcome $[7,13]$. 
Very recently, incidence of $6 \mathrm{q}$ deletion and its clinical impact have been studied in CLL. Deletion of $6 \mathrm{q}$ is a rare abnormality detected in 3-6\% of patients and represents a distinct cytogenetic and clinicobiological entity with intermediate prognosis $[14,15]$.

In the present study, we have used iFISH to assess the incidence of the most frequent chromosomal abnormalities, del13q, trisomy 12, del11q, del17p and del6q in a group of 86 CLL patients. Furthermore, the obtained cytogenetic findings were correlated with patients' clinical and laboratory data to identify differences among individual cytogenetic subgroups as defined by the presence or absence of the above chromosomal abnormalities. Duration of the treatment-free intervals (TFIs) in individual genetic subgroups was also analyzed in order to establish whether chromosomal abnormalities can provide an independent prognostic information about the risk of progression in untreated CLL patients.

\section{Patients and methods}

Patients. Eighty-six consecutive CLL patients (53 males and 33 females with a mean age of $65 \pm 9$ years; range: $39-95$ years) were included in this study. Diagnosis of CLL was established according to the WHO criteria [16]. Complete clinical and laboratory data including Rai clinical stage were available in 75 of 86 patients. At diagnosis, 8 (9\%) patients had stage 0; 19 (22\%) stage I; 30 (35\%) stage II; 9 (11\%) stage III; and 9 (11\%) stage IV. In 11 patients (13\%), the clinical stage status was not known. The mean time of follow-up was $52 \pm 39$ months (range 5-147). Four CLL-related deaths were observed during the study period with the overall survival of $33 \pm 51$ months.

Interphase fluorescence in situ hybridization. Single cell supensions of mononuclear cells were obtained from EDTAanticoagulated peripheral blood or bone marrow samples by Ficoll-Urographin (Sigma, Schering; Germany) density centrifugation. Interphase FISH studies were performed on slides containing cells fixed in methanol/acetic $(3: 1, \mathrm{vol} / \mathrm{vol})$ solution and stored at $-20^{\circ} \mathrm{C}$. Analysis of trisomy 12 , del17p, and del13q was performed by iFISH using the following DNA probes purchased from Vysis (USA): CEP12 DNA probe conjugated with spectrum orange (SO), LSI p53 conjugated with SO and LSI 13/RB1 conjugated with SO, respectively. For analysis of del11q and del6q the following DNA probes purchased from Kreatech (NL) were used: ON ATM (11q22)/SE 11 conjugated with spectrum red (SR)/spectrum green (SG) and ON 6q21/ SE 6 conjugated with SR/SG, respectively. Denaturation and hybridization steps were performed using a ThermoBRITE hybridizer (Vysis-Abbott, USA).

Briefly, slides were pre-treated with 0,005\% pepsin in 0,01 M $\mathrm{HCl}$ for $10 \mathrm{~min}$. at $37^{\circ} \mathrm{C}$ with subsequent washing in $1 \mathrm{x} \mathrm{PBS}$ ( $2 \times 5 \mathrm{~min})$. Then, fixation was performed in $1 \mathrm{xPBS} / 20 \mathrm{mM}$ $\mathrm{MgCl}_{2} / 1 \%$ formaldehyde for $10 \mathrm{~min}$. at room temperature (RT). After double washing in $1 \mathrm{x}$ PBS, the slides were dehydrated in an alcohol series $(70 \%, 90 \%, 100 \%)$ and air-dried at RT. The

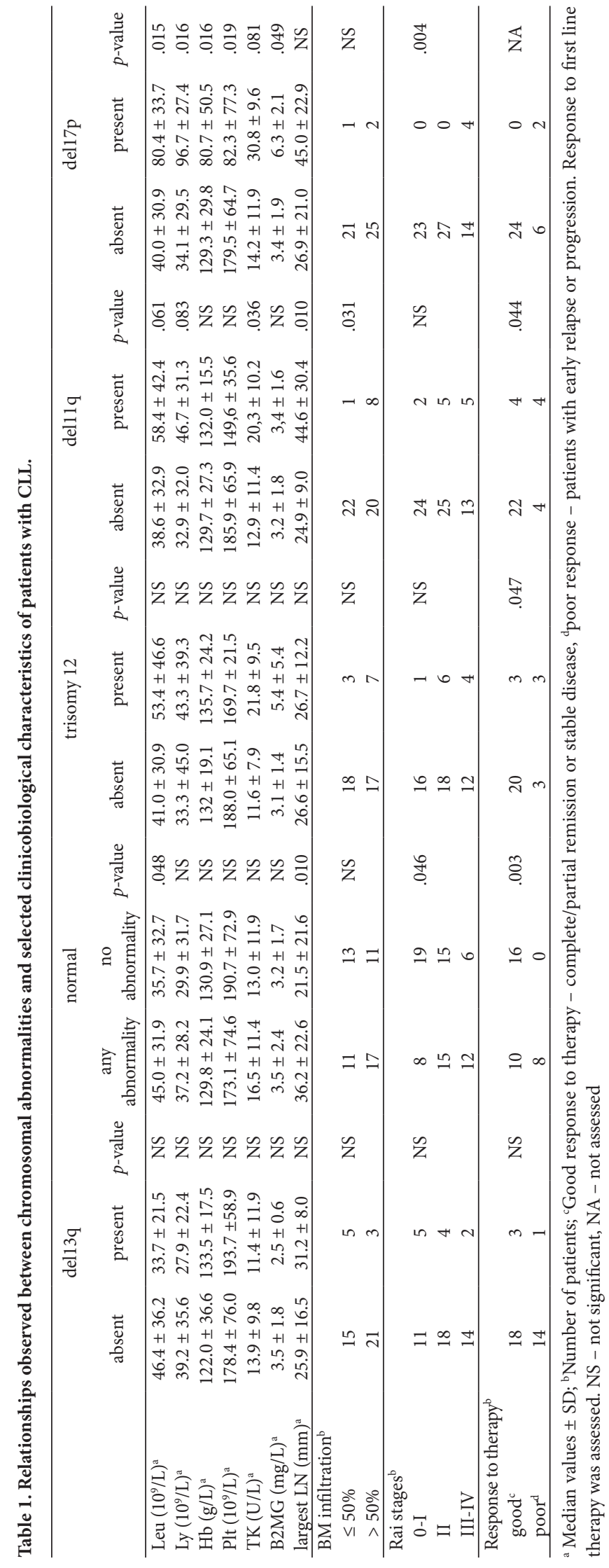


probes were applied and the slides were denaturated at $75^{\circ} \mathrm{C}$ for $6 \mathrm{~min}$. and hybridized overnight at $37^{\circ} \mathrm{C}$. Post-hybridization washing was carried out in $50 \%$ formamide $\mathrm{pH} 7.0$, for $5 \mathrm{~min}$. and $2 \mathrm{xSSC}$ for $2 \mathrm{~min}$. (both at $46^{\circ} \mathrm{C}$ ). Subsequently, the slides were counterstained with DAPI and the number of hybridization spots and their distribution in the nuclei were evaluated using a BX60 fluorescence microscope (Olympus, Germany) equipped with a 100X oil objective. For each slide, the number of hybridization spots per nucleus was counted in at least 200 nuclei; only spots with a similar size, intensity, and shape were counted. Frequencies of positive nuclei in individual slides ranged from $12-97 \%$ in del13q, $8-70 \%$ in trisomy $12,10-90 \%$ in del11q, $12-90 \%$ in del17p and $24-80 \%$ in del6q.

Statistical analysis. The $\chi^{2}$ test was used to assess associations between categorical variables, while continuous variables were analyzed using the Mann-Whitney or Kruskal-Wallis tests. All tests were two-sided. Treatment-free intervals (TFIs) were estimated by the Kaplan-Meier method. The survival curves were statistically compared by the log-rank (MantelCox) test. The statistical significance was considered to be present once the p-value was $\leq 0.05$. The statistical analyses were performed by means of the SPSS 17.0 software package (SPSS, USA).

\section{Results}

FISH analysis. Of 86 patients studied by iFISH, chromosomal abnormalities were detected in 39 (45\%) patients: $30(77 \%)$ patients had one abnormality and $9(23 \%)$ patients had two or more abnormalities ( 2 abnormalities in 7 patients, 3 abnormalities in 2 patients).

Deletion of 13q was found in 17 out of $55(31 \%)$ analyzed cases, trisomy 12 in 11 out of $58(19 \%), 11$ q deletion in 14 out of $81(17 \%)$ cases, $17 p$ deletion in 5 out of $79(6 \%)$ and $6 q$ deletion in 3 out of 67 (5\%) patients.

Deletion of $13 q$ was detected as a sole abnormality in 11/17 (65\%) patients. In the remaining 6 patients, combinations with the following abnormalities were observed: $11 \mathrm{q}$ deletion (2 patients), trisomy 12 ( 2 patients), $17 \mathrm{p}$ deletion (1 patient) and a triple combination of $13 \mathrm{q}$ deletion/trisomy $12 / 17 \mathrm{p}$ deletion in one patient. Partial biallelic deletion of 13q was detected in 4 out of 17 (24\%) cases and it was present only in those patients who displayed deletion of $13 \mathrm{q}$ as a sole abnormality.

Among 11 patients with trisomy 12 , five $(46 \%)$ had a single abnormality whereas 6 (54\%) had multiple abnormalities. Combinations with $13 \mathrm{q}$ deletion ( 2 patients), $11 \mathrm{q}$ deletion (2 patients) as well as combinations of 13q deletion/trisomy12/ $17 \mathrm{p}$ deletion (1 patient) and trisomy $12 / 11 \mathrm{q}$ deletion/6q deletion (1 patient) were also detected.

Deletion of $11 \mathrm{q}$ was a sole abnormality in 9/14 (64\%) patients while in the remaining 5 patients combinations with $13 q$ deletion, trisomy 12 and a triple combination of trisomy $12 / 11 \mathrm{q}$ deletion/6q deletion were observed (all already mentioned above).

In 3 of 5 patients, deletion $17 p$ was found as a sole abnormality, in one patient it was combined with $13 \mathrm{q}$ deletion and in one a $13 \mathrm{q}$ deletion/trisomy12/17p deletion combination was present.

Of 3 cases with $6 \mathrm{q}$ deletion, two had a single abnormality and one had trisomy 12/11q deletion/6q deletion combination.

Correlation with clinical and laboratory data. When the distribution of chromosomal aberrations in relation to Rai stages at the time of diagnosis was analyzed, there was found a significant accumulation of cases with del17p in the advanced Rai stages $(p=0.004)$. In contrast, normal iFISH results were associated with the early stages of the disease $(p=0.046)$. No significant differences were observed in the distribution of del13q as a sole abnormality, del11q, and trisomy 12. Because of low number of patients, statistical analysis was not executable in cases with del6q. A significant association was also observed between the number of cytogenetic abnormalities and Rai stages $(\mathrm{p}=0.039)$ (Table 2) with accumulation of abnormalities in the advanced stages; all patients with multiple abnormalities had intermediate or advanced Rai stages (II.-IV.) of the disease. There were no significant differences in distribution of abnormalities in relation to patients' gender or age.

The clinical data about treatment were available in 70 patients. Fifty $(71.4 \%)$ of them required therapy; fludarabinebased regimens were administered in 25 patients, chlorambucil or chlorambucil/prednisone in 19 patients, and combina-

Table 2. The incidence of chromosomal abnormalities in CLL patients as detected by iFISH.

\begin{tabular}{|c|c|c|c|c|c|c|c|c|}
\hline Study & $\begin{array}{l}\text { Dohner } \\
\text { et al. [7] }\end{array}$ & $\begin{array}{c}\text { Sindelarova et } \\
\text { al. [9] }\end{array}$ & $\begin{array}{l}\text { Durak } \\
\text { et al.[12] }\end{array}$ & $\begin{array}{l}\text { Bullinger et } \\
\text { al. 17] }\end{array}$ & $\begin{array}{l}\text { Stilgenbauer et } \\
\text { al. [18] }\end{array}$ & $\begin{array}{l}\text { Dewald } \\
\text { et al. [19] }\end{array}$ & $\begin{array}{l}\text { Glassman } \\
\text { et al. [20] }\end{array}$ & Present study \\
\hline No. of patients & 325 & 217 & 79 & 258 & 139 & 113 & 100 & 86 \\
\hline del13q & $55 \%$ & $54 \%$ & $33 \%$ & $62 \%$ & $51 \%$ & $64 \%$ & $40 \%$ & $31 \%$ \\
\hline del11q & $18 \%$ & $12 \%$ & $5 \%$ & $11 \%$ & $25 \%$ & $15 \%$ & $23 \%$ & $17 \%$ \\
\hline trisomy 12 & $16 \%$ & $16 \%$ & $15 \%$ & $10 \%$ & $12 \%$ & $25 \%$ & $11 \%$ & $19 \%$ \\
\hline del17p & $7 \%$ & $16 \%$ & $8 \%$ & $6 \%$ & $3 \%$ & $8 \%$ & $12 \%$ & $6 \%$ \\
\hline Normal & $18 \%$ & $30 \%$ & $49 \%$ & $22 \%$ & $19 \%$ & $23 \%$ & $36 \%$ & $55 \%$ \\
\hline $\begin{array}{l}\text { Total } \\
\text { abnormalities }\end{array}$ & $82 \%$ & $70 \%$ & $51 \%$ & $78 \%$ & $81 \%$ & $77 \%$ & $64 \%$ & $45 \%$ \\
\hline
\end{tabular}


tion chemotherapy CVP (cyclophosphamide, vincristine, prednisolone) or R-CHOP (rituximab, cyclophosphamide, doxorubicine, vincristine, prednisolone) in the remaining 6 patients. The time to progression as indicated by the treatment-free interval (TFI) was estimated using the Kaplan-Meier method (Graph 1). Overall, significant differences ( $p=0.027$ ) among curves were found by the log-rank (Mantel-Cox) test. The mean duration of TFI was $23 \pm 30$ months. The shortest time from the date of diagnosis to the date of first treatment was observed in groups with $17 \mathrm{p}$ and $11 \mathrm{q}$ deletions (10 and 12 months, respectively). Thirteen of 14 patients (92\%) in these groups eventually required therapy. The mean TFI interval in patients with trisomy 12 was 14 months. The longest mean TFIs were observed in patients with normal cytogenetics (38 months) and $13 \mathrm{q}$ deletion (68 months). What is more, over one third of patients in these groups did not require therapy at all.

When the response to treatment was assessed (complete/ partial remission or stable disease versus early relapse or progression) the best response rate was observed in patients without any abnormality ( $\mathrm{p}=0.003)$, all of them achieving complete/partial remission or stable disease. In contrast, the probability of achieving complete/partial remission or stable disease was significantly lower in patients with trisomy 12 and deletion of $11 \mathrm{q}(\mathrm{p}=0.047$ and $\mathrm{p}=0.044$, respectively). In the group with $17 \mathrm{p}$ deletion, the clinical data about therapy were available only in 3 patients; one of them is currently receiving first line therapy while in the remaining 2 patients, the resistance to fludarabine-based regimens was observed (statistical analysis not performed).

Due to the short time of follow-up and a small number of patients, statistical analysis of overall survival in correlation to FISH abnormalities could not be performed.

In addition to the shortest TFI, the group of patients with $17 p$ deletion manifested with several distinct laboratory and clinical features, namely higher leukocyte $(\mathrm{p}=0.015)$ and lymphocyte $(\mathrm{p}=0.016)$ counts, lower hemoglobin levels $(\mathrm{p}=0.016)$, lower platelet counts $(\mathrm{p}=0.019)$ and higher $\beta$-2-microglobulin levels ( $p=0.049)$; a tendency to higher thymidine kinase (TK) levels was also observed $(\mathrm{p}=0.081)$. The group with deletion of $11 \mathrm{q}$ was characterized by significantly higher levels of TK $(p=0.036)$, higher degree of bone marrow infiltration $(p=0.031)$ and by larger lymph node diameter measured $(\mathrm{p}=0.013)$; though not significant, higher leukocyte and lymphocyte counts were also present ( $\mathrm{p}=0.061$ and 0.083 , respectively). On the other hand, significantly smaller lymph node diameter $(p=0.004)$ and lower leukocyte counts $(p=0.025)$ were observed in patients with normal iFISH findings.

\section{Discussion}

We evaluated the incidence of the most common chromosomal abnormalities, 13q deletion, trisomy 12, 11q deletion and $17 p$ deletion, together with one of the less frequently studied abnormalities, deletion of $6 \mathrm{q}$, by using interphase

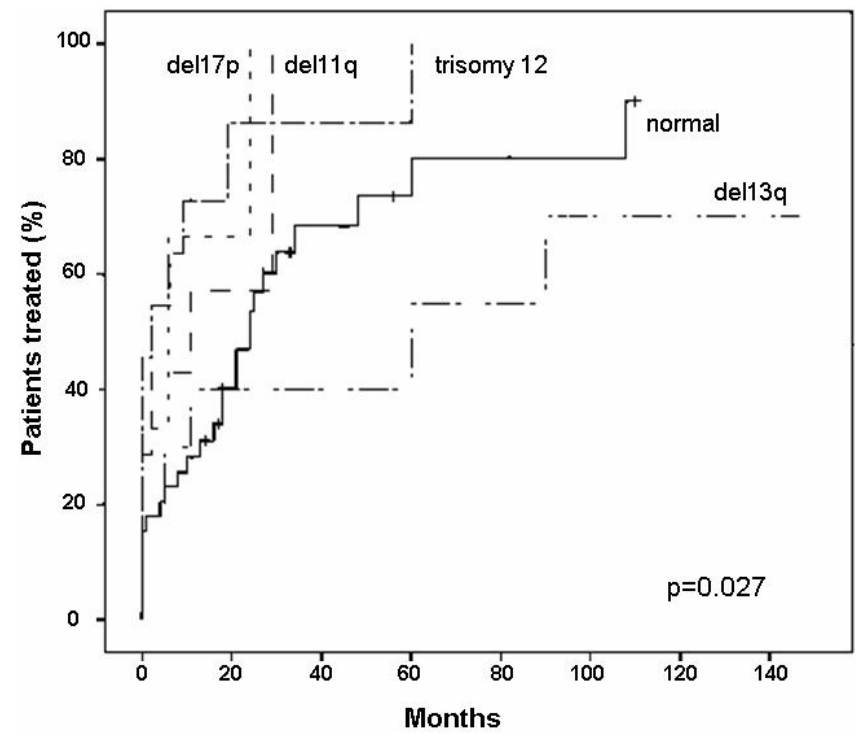

Figure 1. The probability of disease progression as defined by the treatment-free interval in the five different genetic subgroups. The mean treatment-free intervals in subgroups with $17 \mathrm{p}$ deletion, $11 \mathrm{q}$ deletion, $12 \mathrm{q}$ trisomy, normal karyotype, and $13 q$ deletion as a sole abnormality were $10,12,14,38$, and 68 months, respectively. The differences between the curves were statistically significant $(\mathrm{p}=\mathbf{0 . 0 2 7})$.

fluorescence in situ hybridization in CLL patients. In our group of 86 patients, the total frequency of abnormalities was $45 \%$, which is slightly lower when compared to $51-82 \%$ detected in previous studies (Table 2). Potential parameters that may have influenced the overall frequencies of chromosomal abnormalities include the scale of chromosomal abnormalities studied, molecular cytogenetic method [9], as well as the composition of the group of patients (clinical stage, disease progression, treatment history) [21].

The most frequent abnormality was deletion of $13 q$ found in $17 / 55$ (31\%) of cases while the incidence in previous reports ranged from 33 to $62 \%$ (Table 2). Deletion of $13 q$ was a sole abnormality in 11/17 (65\%); similar frequencies (66-75\%) have been observed before [7-10, 12, 17-20]. Frequencies of trisomy 12 , del11q and del17p in the present study are in a range established by iFISH in previous studies as reviewed in Tab. 2. In the present study, deletion of $6 \mathrm{q}$ was detected in $5 \%$ of papients as as compared to 3-6\% reported before $[14,15]$.

Biallelic 13q deletion has been reported in previous studies in the range of 9 to $17 \%$ of total cases with 13q deletion [23-24] as compared to $24 \%$ in our study. It has been suggested that biallelic del13q represents a more aggressive chromosomal abnormality than monoallelic deletion and is associated with an inferior progression free survival and a more frequent need of treatment $[24,25]$.

In accordance with other studies $[7,9]$, combinations of different chromosomal abnormalities were also detected. In the present study, the chromosomal abnormalities that were 
most frequently combined with other abnormalities were trisomy 12 and $13 \mathrm{q}$ deletion (55\% and 35\%, respectively), a finding comparable to the data published by Sindelarova et al. [9] (46\% and $38 \%$, respectively). This suggests that CLL is a genetically unstable disease and clonal evolution is common in B-CLL patients [25-27].

We also observed differences in the distribution of abnormalities among individual Rai stages with higher frequency of del17p in the advanced stages and normal cytogenetics in the early stages of the disease. This is congruent with the findings previously reported by Döhner et al. [7]. In addition, more advanced disease stages were characterized by an accumulation of several abnormalities, as observed in both the present and a previous study by Durak et al. [12].

Furthermore, we observed significant differences in TFI duration among different cytogenetic subgroups. The shortest mean TFIs were observed in groups with deletions of $17 \mathrm{p}$ and $11 \mathrm{q}$, and trisomy 12 (10,12 and 14 months, respectively) as compared to long TFIs in groups with normal FISH findings or $13 q$ deletion as a sole abnormality ( 38 and 68 months, respectively). Similar results have been observed before $[7,28]$ with the exception of trisomy 12 in which intermediate TFI would be expected. We have therefore analyzed the composition of our group of patients with trisomy 12, but no significant differences in sex, age or clinical stage were found between these and other patients in the present study. Moreover, in patients with deletions of $17 \mathrm{p}$ and $11 \mathrm{q}$, the need of therapy was higher (92\% patients treated) than in groups with normal cytogenetic findings or 13q deletion in which over one third of patients did not require therapy during the whole follow-up period.

The existence of associations between chromosomal abnormalities and the response to fludarabine-based regimens has been demonstrated before. The deletion of TP53 has been shown to be associated with resistance to treatment with alkylators, fludarabine and rituximab in a number of clinical studies [29-33]. In our group of patients, the data concerning response to therapy were available only in two patients with $17 \mathrm{p}$ deletion, both of them being resistant to treatment. Furthermore, a poor response to therapy was found in patients with $11 \mathrm{q}$ deletion and trisomy 12 in our study. In contrast, all patients having normal iFISH findings achieved complete or partial remission. Surprisingly, the response rate was not positively affected by the presence of $13 \mathrm{q}$ deletion, although this group is otherwise characterized by longer TFI and OS [7]. This indicates that better prognosis in this group might be influenced by other clinical and biological features.

In the present study, patients with $11 \mathrm{q}$ deletion exhibited extensive bone marrow infiltration and lymphadenopathy, as reported previously $[7,34]$.

In summary, we have identified significant differences in clinical and biological characteristics and outcome among different genetic subgroups of CLL patients defined by chromosomal abnormalities as detected by iFISH. Patients with deletion of $13 q$ were characterized by stable disease with the longest TFI. Normal genetic findings by iFISH predicted for intermediate TFI, low tumor burden and a very good response to standard treatment. In contrast, rapid disease progression and poor response to treatment were observed in patients with trisomy 12, deletion of $11 \mathrm{q}$ and deletion of $17 \mathrm{p}$. Additionally, deletion of $17 \mathrm{p}$ was associated with the highest tumor burden and disease activity as reflected by the advanced clinical stages and corresponding laboratory data. Overall, the present study confirms a high prognostic impact of chromosomal abnormalities as detected by iFISH in predicting prognosis and response to therapy in CLL patients what may enable more reliable decisions for clinical management.

Acknowledgments. This work was supported by grants VVGS 57/0910 and VEGA 1/0297/10. The work was also supported by Slovak Research and Development Agency under contracts No. APVT-20-032504 and APVV-20-052005 as well as by the League Against Cancer, Slovakia (Liga proti rakovine SR).

\section{References}

[1] REDAELLI A, LASKIN BL, STEPHENS JM, BOTTEMAN MF, PASHOS CL. The clinical and epidemiological burden of chronic lymphocytic leukaemia. Eur J Cancer Care 2004; 13: 279-287. doi:10.1111/j.1365-2354.2004.00489.x

[2] RAI KR, SAWITSKY A, CRONKITE EP, CHANANA AD, LEVY RN et al. Clinical staging of chronic lymphocytic leukemia. Blood 1975; 46: 219-234.

[3] BINETJL,AUQUIERA,DIGHIEROG,CHASTANGC,PIGUET $\mathrm{H}$ et al. A new prognostic classification of chronic lymphocytic leukemia derived from a multivariate survival analysis. Cancer 1981;48: 198-206. doi:10.1002/1097-0142(19810701)48:1<198:: AID-CNCR2820480131>3.0.CO;2-V

[4] BINET JL, CALIGARIS-CAPPIO F, CATOVSKY D, CHESON $B$ et al. Perspectives on the use of new diagnostic tools in the treatment of chronic lymphocytic leukemia. Blood 2006; 107: 859-861. doi:10.1182/blood-2005-04-1677

[5] MONTILLO M, HAMBLIN T, HALLEK M, MONTSERRAT E, MORRA E. Chronic lymphocytic leukemia: novel prognostic factors and their relevance for risk-adapted therapeutic strategies. Haematologica 2005; 90: 391-399.

[6] JULIUSSON G, OSCIER DG, FITCHETT M, ROSS FM, STOCKDILL G et al. Prognostic subgroups in B-cell chronic lymphocytic leukemia defined by specific chromosomal abnormalities. N Engl J Med 1990; 323: 720-724. doi:10.1056/ NEJM199009133231105

[7] DÖHNER H, STILGENBAUER S, BENNER A, LEUPOLT E, KRÖBER A et al. Genomic aberrations and survival in chronic lymphocytic leukemia. N Engl J Med 2000; 343: 1910-1916. doi:10.1056/NEJM200012283432602

[8] STILGENBAUER S, BULLINGER L, LICHTER P, DOHNER H. Genetics of chronic lymphocytic leukemia: genomic aberrations and $\mathrm{V}(\mathrm{H})$ gene mutation status in pathogenesis and clinical course. Leukemia 2002; 16: 993-1007. doi:10.1038/ sj.leu. 2402537

[9] SINDELAROVA L, MICHALOVA K, ZEMANOVA Z, RANSDORFOVA S, BREZINOVA J et al. Incidence of chro- 
mosomal anomalies detected with FISH and their clinical correlations in B-chronic lymphocytic leukemia. Cancer Genet Cytogenet 2005; 160: 27-34. doi:10.1016/j.cancergen cyto.2004.11.004

[10] RIPOLLÉS L, ORTEGA M, ORTUÑO F, GONZÁLEZ A, LOSADA J et al. Genetic abnormalities and clinical outcome in chronic lymphocytic leukemia. Cancer Genet Cytogenet 2006; 171: 57-64. doi:10.1016/j.cancergencyto.2006.07.006

[11] DÖHNER H, STILGENBAUER S, JAMES MR, BENNER A, WEILGUNI T et al. 11q deletions identify a new subset of Bcell chronic lymphocytic leukemia characterized by extensive nodal involvement and inferior prognosis. Blood 1997; 89: 2516-2522.

[12] DURAK B, AKAY OM, ASLAN V, OZDEMIR M, SAHIN F et al. Prognostic impact of chromosome alterations detected by FISH in Turkish patients with B-cell chronic lymphocytic leukemia. Cancer Genet Cytogenet 2009; 188: 65-69. doi:10.1016/j.cancergencyto.2008.08.019

[13] DÖHNER H, STILGENBAUER S, DÖHNER K, BENTZ M, LICHTER P. Chromosome aberrations in B-cell chronic lymphocytic leukemia: reassessment based on molecular cytogenetic analysis. J Mol Med 1999; 77: 266-281. doi:10.1007/s001090050350

[14] CUNEO A, RIGOLIN GM, BIGONI R, DE ANGELI C, VERONESE A et al. Chronic lymphocytic leukemia with 6q- shows distinct hematological features and intermediate prognosis. Leukemia 2004; 18: 476-483. doi:10.1038/sj.leu.2403242

[15] STILGENBAUER S, BULLINGER L, BENNER A, WILDENBERGER K, BENTZ M et al. Incidence and clinical significance of $6 \mathrm{q}$ deletions in B cell chronic lymphocytic leukemia. Leukemia 1999; 13: 1331-1334.

[16] SWERDLOW SH, CAMPO E, HARRIS NL, JAFFE ES, PILERI SA et al. WHO Classification of Tumours of Haematopoietic and Lymphoid Tissues. Lyon: IARC Press, 2008.

[17] BULLINGER L, KRAUTLE C, BUSCH R, KROBER A, EMMERICH $\mathrm{B}$ et al. Incidence and correlation of genomic aberrations with clinical and biological risk factors in B-CLL stage Binet-A within the CLL1 trial of the GCLLSG. [abstract] Blood 2001; 98: 359a.

[18] STILGENBAUER S, RITGEN M, BULLINGER L, KROBER A, LICHTER P et al. Genomic aberrations in the CLL3 trial of the German CLL Study: deletion 11q23 identifies patients with molecular disease persistence after autologous high dose therapy. [abstract] Blood 2001; 98: 763a.

[19] DEWALD GW, BROCKMAN SR, PATERNOSTER SF, BONE ND, O'FALLON JR et al. Chromosome anomalies detected by interphase fluorescence in situ hybridization: correlation with significant biological features of B-cell chronic lymphocytic leukaemia. Br J Haematol 2003; 121: 287-295. doi:10.1046/ j.1365-2141.2003.04265.x

[20] GLASSMAN AB, HAYES KJ. The value of fluorescence in situ hybridization in the diagnosis and prognosis of chronic lymphocytic leukemia. Cancer Genet Cytogenet 2005; 158: 88-91. doi:10.1016/j.cancergencyto.2004.08.012

[21] STILGENBAUER S, SANDER S, BULLINGER L, BENNER A, LEUPOLT E et al. Clonal evolution in chronic lymphocytic leukemia: acquisition of high-risk genomic aberrations asso- ciated with unmutated $\mathrm{VH}$, resistance to therapy, and short survival. Haematologica 2007; 92: 1242-1245. doi:10.3324/ haematol.10720

[22] CARTY P, MORRIS T, MCCABE S, BERMINGHAM C, KELLY J et al. Biallelic deletions of chromosome 13q are frequent at diagnosis in chronic lymphocytic leukaemia. Ulster Med J 2009; 78: 65-74.

[23] CHENA C, AVALOS JS, BEZARES RF, ARROSSAGARAY G, TURDÓ K et al. Biallelic deletion 13q14.3 in patients with chronic lymphocytic leukemia: cytogenetic, FISH and clinical studies. Eur J Haematol 2008; 81: 94-99. doi:10.1111/j.16000609.2008.01086.x

[24] O'CONNOR SJ, TURNER K, BARRANS SL, DICKINSON B, RAWSTRON AC et al. Bi-Allelic Deletion of 13q14 Is Associated with Inferior Progression Free Survival Compared to Mono-Allelic 13q14 Deletion in B-Cell Chronic Lymphocytic Leukaemia. Blood (ASH Annual Meeting Abstracts) 2005; 106: 2936

[25] BERKOVA A, ZEMANOVA Z, TRNENY M, SCHWARZ J, KARBAN J et al. Clonal evolution in chronic lymphocytic leukemia studied by interphase fluorescence in-situ hybridization. Neoplasma 2009; 56: 455-458. doi:10.4149/ neo $2009 \quad 05 \quad 455$

[26] STILGENBAUER S, SANDER S, BULLINGER L, BENNER A, LEUPOLT E et al. Clonal evolution in chronic lymphocytic leukemia: acquisition of high-risk genomic aberrations associated with unmutated $\mathrm{VH}$, resistance to therapy, and short survival. Haematologica 2007; 92: 1242-1245. doi:10.3324/ haematol.10720

[27] SHANAFELT TD, WITZIG TE, FINK SR, JENKINS RB, PATERNOSTER SF et al. Prospective evaluation of clonal evolution during long-term follow-up of patients with untreated early-stage chronic lymphocytic leukemia. J Clin Oncol 2006; 24: 4634-4641. doi:10.1200/ JCO.2006.06.9492

[28] DÖHNER H, STILGENBAUER S, JAMES MR, BENNER A, WEILGUNI T et al. 11q Deletions Identify a New Subset of B-Cell Chronic Lymphocytic Leukemia characterized by Extensive Nodal Involvement and Inferior Prognosis. Blood 1997; 87: 2516-2522.

[29] GREVER MR, LUCAS DM, DEWALD GW, NEUBERG DS, REED JC et al. Comprehensive assessment of genetic and molecular features predicting outcome in patients with chronic lymphocytic leukemia: results from the US Intergroup Phase III Trial E2997. J Clin Oncol 2007; 25: 799-804. doi:10.1200/ LCO.2006.08.3089

[30] BYRD JC, SMITH L, HACKBARTH ML, FLINN IW, YOUNG $\mathrm{D}$ et al. Interphase cytogenetic abnormalities in chronic lymphocytic leukemia may predict response to Rituximab. Cancer Res 2003; 63: 36-38.

[31] STURM I, BOSANQUET AG, HERMANN S, GÜNER D, DÖRKEN B et al. Mutations of p53 and consecutive selective drug resistance in B-CLL occurs as a consequence of prior DNA-damaging chemotherapy. Cell Death Differ 2003; 10: 477-484. doi:10.1038/sj.cdd.4401194

[32] DÖHNER H, FISCHER K, BENTZ M. p53 gene deletions predicts for poor survival and non-response to therapy with 
purine analogues in chronic B-cell leukemias. Blood 1995; 85: 1580-1589.

[33] WATTEL E, PREUDHOMME C, HEUCQUET B, M VANRUMBEKE, B QUESNEL et al. p53 mutations are associated with resistance to chemotherapy and short survival in hematologic malignancies. Blood 1994; 84: 3148-3157.
[34] DÖHNER H, STILGENBAUER S, JAMES MR, BENNER A, WEILGUNI $\mathrm{T}$ et al. 11q deletions identify a new subset of Bcell chronic lymphocytic leukemia characterized by extensive nodal involvement and inferior prognosis. Blood 1997; 89: 2516-2522. 